\title{
FOLLOW-UP STUDY OF MACROCEPHALIC CHILDREN WITH ENLARGEMENT OF THE SUBARACHNOID SPACE
}

\author{
J. L. D. GHERPELLI * - V. SCARAMUZZI* - M. L. G. MANREZA * \\ A. J. DIAMENT *
}

SUMMARY - Eighteen macrocephalic children with enlargement of the subarachnoid space (ESAS), with or without mild ventricular dilatation, were followed prospectively to a mean age of 56 months. All were born at term, with uneventful neonatal period and negative tests for congenital infections. There were 17 boys and 1 girl and the mean follow-up period was 46 months (8-58 months). The initial neurologic evaluation, between ages of 2 to 33 months, disclosed abnormalities in 2 cases. At the follow-up one was still abnormal and the other had a normal neurological examination. Another child, who had a normal neurological examination at the age of 5 months, at the age of 7 years and 7 months had an IQ of 77 . Thus the abnormality rate at follow-up was $11 \%$. The OFC returned to the normal range in $45 \%$ of the children at the follow-up period. There were no cases of intracranial hypertension. Gne infant had subdural taps performed at the age of 13 months that disclosed a fluid with the same characteristics as the CSF. All the children had a CT-scan performed at the beginning of the study that revealed a large subarachnoid space; in $77 \%$ it was associated with mild ventricular dilatation. Eleven had CT-scans repeated, during the study period, which showed resolution of the process in 3 cases, improvement in 2 , and unchanged in 6 . We conolude that enlargement of the subarachnoid space in macrocephalic children is often a benign entity. ESAS and macrocephaly will still be present in the majority of children in the long-term follow-up.

KEY WORDS: macrocephaly, subarachnoid space, hydrocephalus.

Estudo evolutivo de criancas macrocefálicas com alargamento do cspaco sub-aracnóideo.

RESUMO - Trata-se de estudo prospectivo de 18 crianças com macrocefalia por aumento do espaço sub-aracnóideo, com ou sem diratação ventricular, seguidas até idade em média de 56 meses. Todas nasceram a termo, sem intercorrèncias perinatais e com testes negativos para TORCH. O tempo médio de seguimento foi 46 meses. Havia 17 meninos e apenas uma menina no grupo estudado. A porcentagem de anormalidades neurológicas no seguimento foi de $11 \%$. Durante o seguimento, o perímetro cefálico retornou aos níveis da normalidade em 45\% das crianças. Nenhum caso desenvolveu hipertensão intracraniana durante o estudo. Todas as crianças realizaram TAC de crânio como parte da avaliação inicial e, além do aumento do espaço sub-aracnóideo peri-encefálico, 77\% delas apresentavam discreta dilatação ventricular. No seguimento, 11 realizaram TAC de controle que revelaram resolução completa do processo em 3 casos, melhora em 2 e permianeceram inalteradas em 6 . Concluimos que o aumento do espaço sub-aracnóideo $€ \mathrm{In}$ crianças macrocefálicas é entidade que apresenta bom prognóstico neurológico na maioria dos casos e que a macrocefalia e o aumento do sub-aracnóideo continuarão presentes, na maioria das crianças, no seguimento a longo prazo.

PALAVRAS-CHAVE: macrocefalia, espaço sub-aracnóideo, lidrocefalia.

* Division of Child Neurology, Department of Neurology, Clinics Hospital, University of Sao Paulo Medical School.

Dr. Jose Luiz Dias Gherpelli - Servigo de Neurologia Infantil, Departamento de Neurologia, Hospital das Clínicas, Fraculdade de Medicina, Universidade de São Paulo - Caixa Postal 3461 - 01060 São Paulo SP - Brasil. 
During infancy, measurement of occipito-frontal circumference (OFC) is a good method of monitoring the increase of intracranial volume. Abnormal head growth during the first year of life is a frequent cause of referral to the pediatric neurologist. In recent years neuroimaging techniques brought a considerable simplification to the etiological diagnosis of abnormal head growth. Macrocephaly is a term used to define patients who have an abnormally high OFC. There is no consensus of what is the superior limit of normality above which the child is diagnosed as macrocephalic. Most authors consider the 90th or 97.5th percentile, or above $2 \mathrm{SD}$ of the mean for the infant's age 1,2,6,11. The main causes of macrocephaly in infancy are: hydrocephalus, megalencephaly, subdural hematomas or effusions, arachnoid cysts, tumors, central nervous system malformations, intracranial abscess. In the last fifteen years, CT-scan and later cranial ultrasonography (US) showed that a considerable number of macrocephalic infants had an abnormal amount of cerebrospinal fluid (CSF) in the subarachnoid space over the frontal region, with normal or mildly dilated ventricles, without evident signs of intracranial hypertension. Fukuyama et al. 4 were the first to describe tomographically the enlargement of the subaracnnoid space (ESAS) in a study of 89 neurologically normal subjects, 43 of them children below the age of 10 years; they concluded that the visualization of the subarachnoid space in the frontal region beyond the age of 2 is always abnormal, while in the first and second years values above $8 \mathrm{~mm}$ and above $4 \mathrm{~mm}$, respectively, were abnormal. The first authors describing these findings concluded that they were cases of arrested external hydrocephalus 12 . The terms «extra-ventricular obstructive hydrocephalus», «benign subdural effusions of infancy», «benign enlargement of the subarachnoid space», «benign extra-axial collection of infancy», «benign extra-cerebral fluid collections», «external hydrocephalus» have all been used to refer to these findings $1-3,6,8,11$. Gooskens et al.5 studying CT-scans of macrocephalic children based on the measurement of the intracranial volume divided their cases in three groups: the children were classified as megalencephalic when the cerebral volume 'was increased; the other two groups had an increase of the CSF and were further sub-divided; those with isolated ventricular dilatation were classified as hydrocephalic and those with ESAS and no ventricular dilatation as «extra-ventricular hydrocephalus». There were 5 children in the last group, 3 of them with mild neurological abnormalities (hypotonia, clumsiness and coordination disturbance). The association of ESAS and subdural effusions was reported 1 , CSF shunting performed in selected cases 3,7,11 and neurodevelopmental abnormalities were detected at the follow-up in some cases 3,11,12. However, most studies showed that the majority of such infants have a normal development 1,2,5,7,11. The pathogenesis of ESAS in macrocephalic children is unknown. The hypothesis of a transitory dysfunction of the CSF dynamics, depending on maturational processes at the arachnoid villosities located in the superior sagital sinus, is supported by recent findings of radionuclide cisternography studies 3 . The actual incidence of ESAS in macrocephalic children without overt intracranial hypertension is unknown.

This study deals with a group of macrocephalic infants diagnosed by CT-scan as having ESAS who were prospectively followed up. Our goal is to provide further clinical, developmental and tomographic information about their long-term outcome.

\section{PATIENTS AND METHOD}

The study group consisted of 18 macrocephalic infants, all born at term gestational age, without perinatal complications. There was only one girl in the group and the mean lage at the first visit was 10 months (range 2-33 $\mathrm{m}$ ). All the infants had OFC at or above the 97.5 percentile and had an initial CT-scan demonstrating ESAS. Cranial CT-scan was performed initially in all cases and 11 children had examination repeated during the followup period. Thirteen infants had cranial US performed during the follow-up period.

The follow-up visits were scheduled each 3 months, during the first year, and once a year from there on. Each visit consisted of a full neurologic examination and the OFC was recorded with a common tape. The mean follow-up period was 46 months (range 8-58m.). The last evaluation occurred at ages varying from 17 to 106 months of age (mean $56 \mathrm{~m}$.). Only the first and last evaluations were considered in the interpretation of the results. Twelve children had psychological tests (Stanford-Binet in children above 5 y. and Brunet-Lezine in those below this age) performed during the follow-up period. All infants had negative test for TORCH and none had images compatible with CNS malformations on the imaging studies. No possible causal etiology was found that explained macrocephaly and the subarachnoid enlargement.

The OFC charts used were those of Marcondes 7 for Brazilian infants up to 3 years and of Nellhaus 9 from there on. 


\section{RESULTS}

General data of the study group are shown in Table 1. The neurological examination was abnormal in 2 infants at the first evaluation. The abnormalities consisted of moderate hypotonia (case 3) and delayed developmental milestones (case 10). However, only one of them (case 10) still had an abnormal examination at the last follow-up visit, at the age of 3 years/9 months. The child had a moderate language delay without focal neurological signs. The neurological examination of the other child (case 3) was normal at 6 years old.

The other child who developed a neurological abnormality during the follow-up period had a normal neurological examination at 5 months of age (case 13). At 7 1/2 years, the child attended a special class with a diagnosis of mild mental retardation (Table 1 ).

Psychological evaluations were performed in 12 cases, being abnormal in one (case 13). In 2 children the results were in the lower range (cases 3 and 8 ). The others had IQ or $D Q$ in the normal range $(>80)$.

Thus the incidence of neurodevelopmental abnormalities in the study was $11 \%(2 / 18)$

The OFC remained at or above the 97.5 percentile in 10 cases (55\%). The OFC normalized in 8 children during the study period (Table 1).

The results of neuroimaging examinations are shown in Table 2.

Table 1. General data of the stwdy group: age at initial and final evaluation, neurological and psychological examinations and initial and final $O F C$.

\begin{tabular}{|c|c|c|c|c|c|c|c|c|}
\hline Case & Sex & Age/I & Age/F & $\mathrm{OFC} / \mathrm{I}$ & $\mathrm{OFC} / \mathrm{F}$ & $\mathrm{NEx} / \mathrm{I}$ & $\mathrm{NEx} / \mathrm{F}$ & PsE \\
\hline 1 & $\mathbf{M}$ & $7 \mathrm{~m}$ & $60 \mathrm{~m}$ & $=97.5$ & $=75$ & $\mathrm{nl}$ & nl & 94 \\
\hline 2 & $\mathbf{M}$ & $10 \mathrm{~m}$ & $24 \mathrm{~m}$ & $=97.5$ & $=97.5$ & $\mathrm{nl}$ & nl & 110 \\
\hline 3 & $\mathbf{M}$ & $12 \mathrm{~m}$ & $72 \mathrm{~m}$ & $>97.5$ & $>97.5$ & anl & $\mathrm{nl}$ & 85 \\
\hline 4 & $\mathbf{F}$ & $10 \mathrm{~m}$ & $63 \mathrm{~m}$ & $>97.5$ & $<97.5$ & nl & $\mathrm{nl}$ & 116 \\
\hline 5 & $\mathbf{M}$ & $6 \mathrm{~m}$ & $32 \mathrm{~m}$ & $>97.5$ & $>97.5$ & $\mathrm{nl}$ & $\mathrm{nl}$ & 100 \\
\hline 6 & $\mathbf{M}$ & $8 \mathrm{~m}$ & $36 \mathrm{~m}$ & $>97.5$ & $<97 . \overline{5}$ & $\mathrm{nl}$ & $\mathrm{nl}$ & - \\
\hline 7 & $\mathbf{M}$ & $22 \mathrm{~m}$ & $58 \mathrm{~m}$ & $>97.5$ & $>97.5$ & $\mathrm{nl}$ & $\mathrm{nl}$ & 97 \\
\hline 8 & $\mathbf{M}$ & $33 \mathrm{~m}$ & $45 \mathrm{~m}$ & $>97.5$ & $<97.5$ & $\mathrm{nl}$ & $\mathrm{nl}$ & 89 \\
\hline 9 & $\mathbf{M}$ & $2 \mathrm{~m}$ & $36 \mathrm{~m}$ & $=97.5$ & $>97.5$ & $\mathrm{nl}$ & $\mathrm{nl}$ & 100 \\
\hline 10 & $\mathbf{M}$ & $12 \mathrm{~m}$ & $45 \mathrm{~m}$ & $>97.5$ & $<97.5$ & anl & anl & - \\
\hline 11 & $\mathbf{M}$ & $4 \mathrm{~m}$ & $71 \mathrm{~m}$ & $>97.5$ & $>97.5$ & nl & $\mathrm{nl}$ & 94 \\
\hline 12 & $\mathbf{M}$ & $8 m$ & $106 \mathrm{~m}$ & $>97.5$ & $<97.5$ & nl & nl & 100 \\
\hline 13 & $\mathbf{M}$ & $5 \mathrm{~m}$ & $91 \mathrm{~m}$ & $>97.5$ & $>97.5$ & $\mathrm{nl}$ & anl & 77 \\
\hline 14 & $\mathbf{M}$ & $10 \mathrm{~m}$ & $37 \mathrm{~m}$ & $=97.5$ & $=50$ & $\mathrm{nl}$ & nl & - \\
\hline 15 & $\mathbf{M}$ & $9 \mathrm{~m}$ & $17 \mathrm{~m}$ & $=97.5$ & $>97.5$ & $\mathrm{nl}$ & $\mathrm{nl}$ & - \\
\hline 16 & $\mathbf{M}$ & $8 \mathrm{~m}$ & $73 \mathrm{~m}$ & $>97.5$ & $<97.5$ & $\mathrm{nl}$ & $\mathrm{nl}$ & - \\
\hline 17 & $\mathbf{M}$ & $4 \mathrm{~m}$ & $90 \mathrm{~m}$ & $>97.5$ & $>97.5$ & $\mathrm{nl}$ & $\mathrm{nl}$ & - \\
\hline 18 & $\mathbf{M}$ & $12 \mathrm{~m}$ & $53 \mathrm{~m}$ & $>97.5$ & $>97.5$ & $\mathrm{nl}$ & $\mathrm{nl}$ & 97 \\
\hline
\end{tabular}

$A G E / I$, age-initial evaluation; $A G E / F$, age-follow-up; Nex/I, initial neurological examination; $N E x / F$, follow-up neurological examination; OFC/I, initial OFC (in percentile); $O F C / F$, follow-up OFC (in percentile); PsE, psychological evaluation (I.Q. or D.Q.); M, masculine; $F$, feminine; $n l$, normal; anl, abnormal; $m$, months. 
Table 2. Data of tomographic ultrasonographic, psychological and neurological evaluations.

\begin{tabular}{cccc}
\hline Case & CT/I & CT/F & US \\
\hline 1 & VD + ESAS & VD + ESAS & ESAS \\
2 & VD + ESAS & - & ESAS \\
3 & VD + ESAS & VD + ESAS & VD \\
4 & VD + ESAS & VD + ESAS & VD \\
5 & ESAS & nl & nl \\
6 & VD + ESAS & nl & VD \\
7 & ESAS & nl & ESAS \\
8 & VD + ESAS & - & - \\
9 & VD + ESAS & - & VD \\
10 & VD + ESAS & - & vD + ESAS \\
11 & VD + ESAS & VD + ESAS & VD + ESAS \\
12 & VD + ESAS & VD + ESAS & - \\
13 & VD + ESAS & - & - \\
14 & ESAS & VD & - \\
15 & VD + ESAS & - & VD \\
16 & VD + ESAS & - & - \\
17 & VD + ESAS & VD + ESAS & VD \\
18 & ESAS & ESAS & VD \\
& & &
\end{tabular}

$C T / 1$, initial CT-scan; $C T / F$, follow-up $C T$-scan; VD, ventricular dilatation; ESAS, subarachnoid space enlargement; nl, normal.

Of the 18 cranial CT-scans initially performed, 14 (77\%) showed a mild ventricular dilatation besides the subarachnoid enlargemnt. In most of the cases, the subarachnoid enlargement was localized in the frontal region, but sumetimes it extended posteriorly over the parietal and the temporal regions. The CT-scan of a typical case of ESAS is shown in Figure 1.

In the follow-up period the CT-scans were repeated in 11 cases. They were normal in $3(27 \%)$ and remained unchanged in $7(63.5 \%)$. There was resolution of the subarachnoid enlargement in one child (case 14) who developed an isolated mild ventricular dilatation.

Cranial US examinations were performed in 13 infants, after the initial and before the control CT-scan. The examinations showed that 3 infants had isolated ESAS, 7 ventricular dilatation, 2 both and in one the examination was normal. In 4 infants with cranial US there were no follow-up CT-scans (cases 2, 9, 10 and 15). In 2 of them ESAS was still present on the cranial US, one with associated ventricular dilatation. The other 2 had an isolated mild ventricular dilatation. If we consider these last cases, the resolution rate of ESAS was 6/15 (40\%) for the children who had at least one neuroimaging follow-up examination.

Bilateral subdural taps were performed in one infant (case 12) at the age of 13 months. A fluid with the same characteristics of CSF was obtained from the procedure. No child developed clinical signs that suggested intracranial hypertension during the follow-up period. None of the infants required placing of a CSF shunt throughout the study period. 


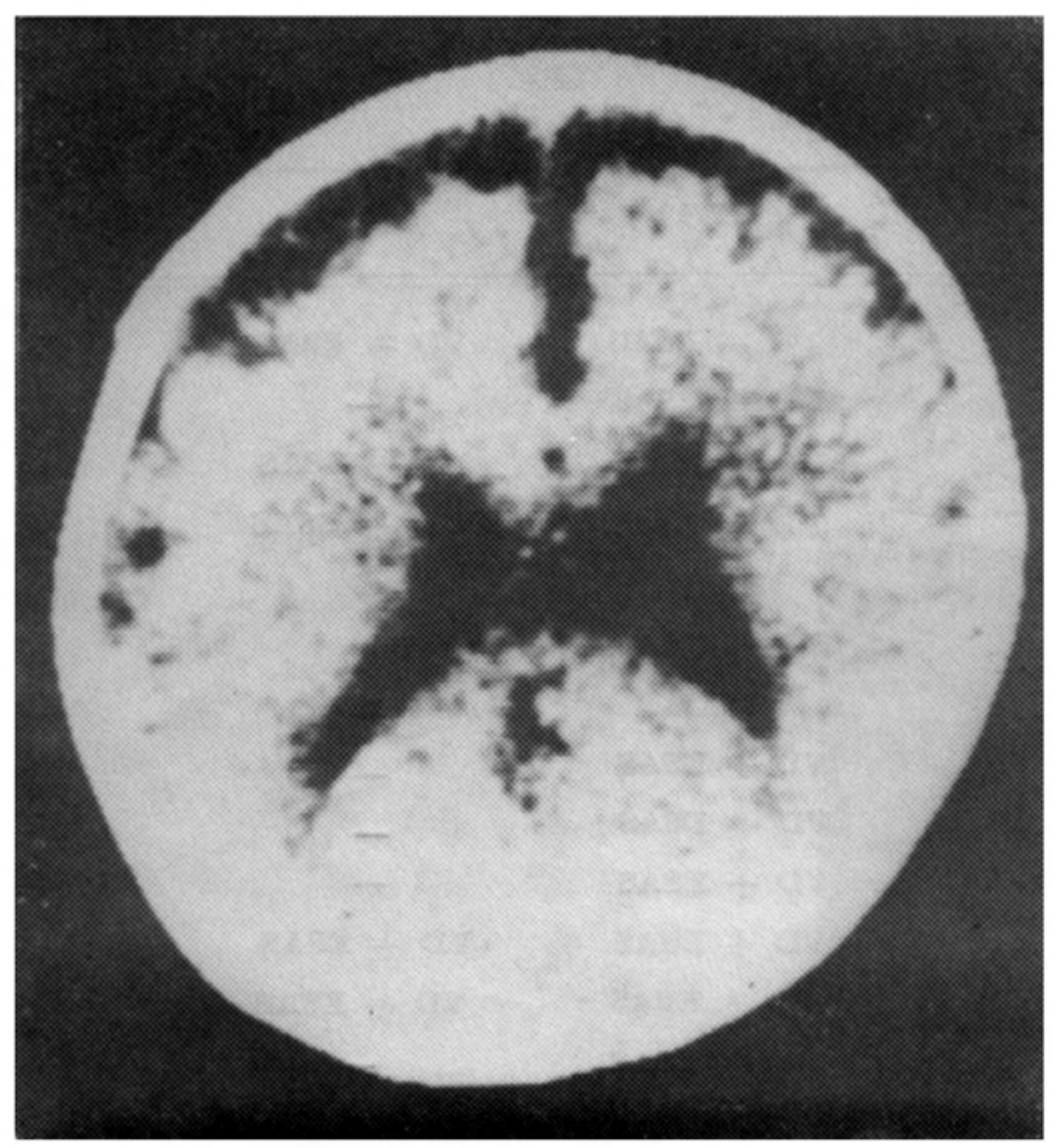

Fig. 1. CT-scan showing typical image of peri-encephalic subarachnoid space enlargement, associated with mild surra-tentorial ventricular dilatation.

\section{COMMENTS}

Our study has shown that ESAS in macrocephalic infants and children has an overall good prognosis with most of the children (89\%) developing normally without any maịor neurological sequelae.

Carolan et al.2 followed 15 infants with macrocephaly and ESAS. All had a normal neurodevelopmental outcome at the follow-up, with ages ranging from 6 to 36 months. The OFC was above the 98th percentile in all infants below 30 months of age at the last follow-up visit, but returned to the normal level in three cases whose ages were in the 30-36 months range. During the second year, they noticed that the OFC paralleled the 98th percentile or «fell» towards it. In a study of 13 macrocephalic infants with ESAS, Hamza et al.6 made a previous selection for normal neurodevelopmental status, they observed that the OFC remained at the initial percentile curve $(>90)$ during the whole follow-up period, which ranged from 3-30 months. Ment et al.8 found $8.3 \%$ of neurological abnormalities in a group of 12 term infants with ESAS followed to a mean age of 17 months, with a mean follow-up of 9 months; only 9 of them were macrocephalic. Five of 6 preterm infants, in the same study, had norma! developmental outcome at ages varying from 12 to 21 months. Nickel and Gallenstein 10 studied a group of 9 infants with ESAS with follow-up ages varying from 24-39 months. During the first year, 7 had mild neurodevelopmental abnormalities which were still present in 4 at the follow-up; mild speech/language and gross motor delays were the neurological findings in most of these children.

De Vries et al.3 studied 7 infants with macrocephaly using magnetic resonance imaging (MRI) and high resolution ultrasonography. They were able to distinguish two groups based on the imaging of the subarachnoid space. Four infants had only one compartment on the MRI and were diagnosed as having «external hydrocephalus». The follow-up, at ages ranging from 9-18 months, showed that development was normal in 2 and the other 2 had gross motor delays. The other group, with 3 infants, had two compartments in the subarachnoid space on the MRI and were 
diagnosed as having subdural effusions, confirmed by the high protein content found at shunting procedures.

Most of the neurological abnormalities reported in these studies are mild developmental delays. Although there are studies that reported severe neurological abnormalities 13 , and the pathogenesis of these abnormalities does not seem to be related to ESAS.

The follow-up period is very important for an adequate evaluation of the children neurological and developmental status. Very often, an infant reported as having a mild hypotonia during the first year of life shows normalization of the neurological examination by the end of the second year. On the other hand, cognitive aspects of development can only be adequately evaluated at school age. In this aspect our study is particularly important, 8 children being at least 5 years old at the follow-up. Our abnormality rate was low $(11 \%)$ and not severe, one child having a language delay and the other a mild mental retardation.

The present study showed that the OFC returned to normal levels $(<97.5$ percentile) in 8 cases $(45 \%)$. Others 6,11 found no normalization at all, while Carolan et al.2 reported a normalization rate of $20 \%$. In several infants a deceleration of cephalic growth was detected during the second year of life. Again, time of follow-up could be the important reason for the differences in normalization rate between our study and the others in the literature. The mean age of the children that normalized their OFC $(58.1 \mathrm{~m})$ was slightly higher than those who were still macrocephalic $(54.4 \mathrm{~m})$ at the follow-up, but the small number of cases did not allow statistical analysis.

There was an evident predominance of male cases in our study, a fact reported in most of the other studies as well 2,6,10-12. There is no apparent reason for this male predominance.

Briner and Bodensteiner 1 performed subdural taps in 2 infants with ESAS who presented mild signs of intracranial hypertension (full fontanel, visible scalp veins, sunset eyes) obtaining a fluid with high protein content and red cell number between 700-7000 per $\mathrm{mm}^{3}$. However, the procedure neither led to any clinical benefit nor to the resolution of ESAS, although in one case they observed a decrease of the subarachnoid space. Subdural effusions are nowadays considered separately from pure ESAS as showed in a recent report 3 . We performed subdural taps in one case obtaining CSF with no resolution of the subarachnoid space enlargement. Normal CSF was also obtained from subdural taps performed in another study 8 . Nowadays, this diagnostic procedure is not used anymore.

Robertson and Gomez 12 reported clinical signs of intracranial hypertension in 5 of 6 infants with ESAS, diagnosed by pneumoencephalography, but only 2 of them required shunting. Another case was described in Ment's study 8, a preterm infant who developed neonatal intracranial hemorrhage and was later shunted. Intracranial hypertension was absent in our study, as in several others $2-4,7,11$. Thus, it seems to exist no reason for considering a shunt procedure in these children.

CT-scans showed associated ventricular dilatation in $77 \%$ of our cases. Several other studies reported a high incidence of ventricular dilatation (above 50\%) in macrocephalic children with ESAS 2,3,6,8,10,12. Concerning the follow-up CT-scans, we found a complete resolution of the subarachnoid enlargement in 3 children (27\%) and, in another child, the ventricles had returned to normal size; in 6 children $(57 \%)$ the scans disclosed no changes. The resolution of ESAS and ventricular dilatation was occasionally reported $2,6,8,11,12$.

Carolan et al.2 were able to detect ESAS in 4/15 cases through cranial US, while we observed it in $5 / 13$ cases. We were not able to compare the results because both examinations (cranial US and CT-scans) were not performed at the same time. The cranial US was not routinely performed in our study because, at the beginning, we had no high frequency transducers adequate to allow visualization of the subarachnoid space below the scalp. De Vries et al.3 were able to detect ESAS with good accuracy using high resolution US and concluded that cranial US and MRI are the best diagnostic procedures for diagnosis in these infants.

Our data suggest that ESAS in macrocephalic children has a good neurological outcome. However the term «benign» should not be used a priori because, in selected 
cases, neurodevelopmental abnormalities can be present in the long-term follow-up. Circulatory dysfunction of the CSF, that may play a role in the process, does not seem to be responsible for the abnormalities found in these children. Until more is known about its pathogenesis we must follow closely these children. Macrocephaly and ESAS will still be present in the long-term follow-up in several of these children.

Acknowledgements - We would like to thank the Psychological Division (Beatriz H.W. Lefevre) for the assistance in the psychological evaluation of the children.

\section{REFERENCES}

1. Briner S, Bodensteiner J. Benign subdural collections of infancy. Pediatrics 1981 67:802-804.

2. Carolan PL, McLaurin RL, Towbin RB, Towbin JA, Egelhof FJC. Benign extra-axial collections of infancy. Pediat Neurosci 1985-86, 12:140-144.

3. De Vries LS, Smet M, Ceulemans B, Marchal G, Wilms G, de Roo M, Plets C, Casaer P. The role of high resolution ultrasound and MRI in the investigation of infants with macrocephaly. Neuropediatrics 1990, 21:72-75.

4. Fukuyama $Y$, Miyao $M$, Ishizu $T$, Maruyama $H$. Developmental changes in normal measurements by computed tomography. Dev Med Child Neurol 1979, 21:425-432.

5. Gooskens RHJM, Willemse J, Faber JA, Verdonck FMM. Macrocephalies: a differentiated approach. Neuropediatrics 1989, 20:1644-169.

6. Hamza M, Bodensteiner JB, Noorani PA, Barnes PD. Benign extracerebral fluid collections: a cause of macrocrania in infancy. Pediat Neurol 1987, 3:218-221.

7. Marcondes E. Normas para o diagnóstico e a classificação dos distúrbios de crescimento e nutrição. Pediatria (São Paulo) 1982, 4:307-326.

†. Ment LR, Duncan CC, Geehr R. Benign enlargement of the subarachnoid spaces in the infant. $J$ Neurosurg 1981, 54:504-508.

9. Nellhaus G. Composite international and interracial graphs. Pediatrics 1968, 41:106-118.

10. Nickel RE, Gallenstein JS. Developmental prognosis for infants with benign enlargement of the subarachnoid spaces. Dev Med Child Neurol 1987, 29:181-186.

11. Pettit RE, Kilroy AW, Allen JH. Macrocephaly with head growth parallel to normal growth pattern. Arch Neurol 1980, 37:518-521.

12. Robertson WC, Gomez MR. External hydrocephalus: early finding in congenital communicating hydrocephalus. Arch Neurol 1978, 35:541-544.

13. Sahar A. Pseudohydrocephalus-megalencephaly, increased intracranial pressure and widened subarachnoid space. Neuropaediatrie 1978, 9:131-139. 